\title{
Perception of palliative medicine by health care professionals at a teaching community hospital: what is the key to a "palliative attitude"?
}

This article was published in the following Dove Press journal: Journal of Multidisciplinary Healthcare

\section{Nga Yu Cheung \\ Anna Gorelik \\ Parag Mehta \\ Louis Mudannayake \\ Arundati Ramesh \\ Thayyllathil Bharathan \\ Gregory Goldenberg}

Department of Medicine, New York Presbyterian Brooklyn Methodist Hospital, Brooklyn, NY, USA

\section{Video abstract}

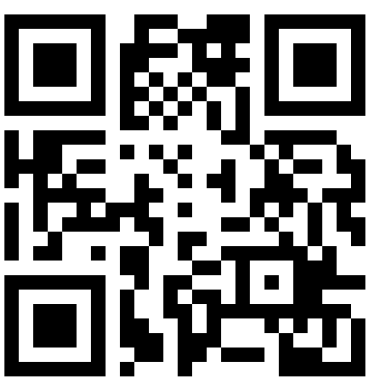

Point your SmartPhone at the code above. If you have a QR code reader the video abstract will appear. Or use: https://youtu.be/h2TFQlvzTxE
Correspondence: Gregory Goldenberg Department of Medicine, New York Presbyterian Brooklyn Methodist Hospital, 2792 Ocean Ave Brooklyn, NY II 229 USA

Tel $+|917692824|$

Email gregonline_2000@yahoo.com
Background: With growing expense in chronic illness and end-of-life (EOL) care, population-based interventions are needed to reduce the health care cost and improve patients' quality of life. The authors believe that promotion of palliative medicine is one such intervention and this promotion depends on the acceptance of palliative medicine concepts by health care professionals.

Aims of the studies: Perception of palliative medicine in chronic illness and in EOL care by health care professionals was learned in two studies carried out at a teaching community hospital 14 years apart.

Participants and methods: Voluntary and anonymous surveys were randomly distributed among physicians, nurses, and social workers/case managers. Participants in the two studies presented two different groups of health care providers.

Results of the studies: Results of the two studies were essentially similar. On most of the issues, respondents' perceptions were consistent with palliative medicine concepts and confidence in palliation grew over the 14-year period. The authors call this approach a "palliative attitude." Physicians with greater experience performed better in care planning. Younger physicians were more perceptive to withdrawal of care in futile cases. Participants' religion had no influence on perception of palliative medicine. Attendance of educational activities did not influence attitudes of health care professionals. Health care providers who favored involvement of palliative care teams in patients' management were better in care planning, interpretation of the DNR consent, use of opioids at the EOL, use of intensive care, and evaluation of the disease trajectory.

Conclusion: The authors conclude that direct interaction between palliative and interdisciplinary teams in clinical practice is the key factor in the education of health care professionals, in the development of a "palliative attitude," and in the promotion of palliative medicine.

Keywords: health care professionals, end-of-life care, chronic illness, palliative care concepts, palliative attitude

\section{Introduction}

A lion share of health care resources, about $\$ 900$ billion/year or over half of the total health care cost, is spent on chronic debilitating conditions and on end-of-life (EOL) care. ${ }^{1}$ By other estimates, the cost of chronic illness is about $84 \%$ of health care expenditures. ${ }^{2}$ Population-level interventions are needed to reduce cost and, at the same time, improve patients' quality of life. ${ }^{1}$ In our opinion, promotion of 
palliative medicine is one such intervention. Palliative medicine addresses treatment of symptoms, goals and plan of care, psychological, and social issues. The complexity of palliation led to recognition of palliative medicine as a specialty. In New York State, the "Palliative Care Information Act," effective February 2011, mandates counseling regarding palliative care for the terminally ill. $^{3}$ Promotion of palliative medicine depends on its perception by health care professionals. Palliative care is delivered by specialized teams and by interdisciplinary teams of health care professionals which include physicians, nurses, and social workers/case managers.

At our teaching community hospital, the palliative care team actively interacts with health care professionals. The interaction involves educational activities such as lectures, seminars, grand rounds, and direct involvement in patients' care. In order for our interaction with interdisciplinary team members to be most effective, we had to learn their attitudes toward issues and concepts of palliative medicine.

\section{Aims of the studies}

We conducted two studies among health care professionals at our teaching community hospital. The first study was carried out shortly after the development of our division, and the second study 14 years later. In these two studies, we: 1) learned perception of chronic illness and EOL issues by health care professionals and their approach to these issues; 2) compared the results of the two studies; and 3) learned factors influencing attitudes of health care professionals. Based on our experience in education and clinical practice, we hypothesized that direct interaction between interdisciplinary and palliative care teams is most essential in understanding and implementing concepts of palliative medicine by health care professionals. A palliative care team helps to manage difficult symptoms, establish a rapport with the patient and caregivers, and define goals and plan of care.

\section{Participants and methods}

The two studies were cross-sectional and conducted at a teaching community hospital with random sampling of the participants. Participation in the studies was voluntary and anonymous. Both studies were approved by the Institutional Review Board (New York Methodist Hospital and Brooklyn Methodist Hospital, New York Presbyterian Healthcare System, affiliate: Weill Medical College of Cornell University), and verbal informed consent of the participants was obtained. The verbal consent was approved by the Institutional Review Board. The first study included physicians and nurses. A survey was conducted among attending physicians and nurses to learn their views on some issues of palliative medicine and guide us in education. The results of the first study were used internally and were not published at that time. Fourteen years later, we conducted a follow-up study where we expanded both the survey questionnaire and the participants' base, enrolling members of interdisciplinary teams such as physicians, nurses, and social workers/case managers. The surveys/questionnaires were randomly distributed among participants at grand rounds, lectures, and in the workplace during a three-day period. The surveys included participants' age, occupation/field of practice, years of experience, and religious affiliation. In the first study, there were 184 participants: 100 (54.5\%) physicians and $84(45.5 \%)$ nurses. In the follow-up study, there were 246 participants: 93 (38\%) attending physicians, 65 (26\%) resident physicians, 74 (30\%) nurses or nurse practitioners, and 14 (6\%) discharge planners/social workers/case managers. In the first study, the participants were asked nine questions and in the second study, the participants were asked 20 questions. In the second study, the answers to questions asked in both studies were compared and the answers to other questions in the second study could not be compared. The data of the studies were analyzed with statistical processing of the data using R software with Fisher's exact test. ${ }^{4}$

\section{Results}

\section{Questions, answers, and comments}

The first part includes questions asked in both studies.

\section{Have you attended seminars/workshops/lectures in} palliative care?

The attendance of these educational activities increased from $14 \%$ to $46 \%(p<0.05)$. In our opinion, this reflects a growing interest of health care professionals in palliative care and the proactive approach of palliative care teams.

\section{Do you discuss advance directives for care in the outpatient setting?}

The rate of positive responses was low in both studies $(38 \%$ and 35\%). Attending physicians discuss advance directives more often than resident physicians ( $49 \%$ vs $14 \%, p<0.05)$ and perform better after 10 years in practice $(56 \%$ vs $38 \%$, $p<0.05)$. Medicine physicians discuss advance directives more often than surgeons $(59.6 \%$ vs $10 \%, p<0.05)$ and gynecologists $(59.6 \%$ vs $33.3 \%, p<0.05)$. Discussion of advance directives requires interaction on multiple visits. ${ }^{5}$ Advance care planning is a process of developing a valid expression of wishes rather than a single consultation event or signing of 
a statutory document. ${ }^{6}$ Physicians who have an established relationship with their elderly functional patients experience positive emotional responses after discussion of advance directives in the outpatient setting. ${ }^{7}$ Our data can be explained by usually longer and better relationships between medicine physicians and their patients than relationships in surgical fields and by a smaller proportion of patients with chronic debilitating illness treated by surgeons and gynecologists.

3. Do you discuss advance directives with patients (or their families/proxies) admitted to the hospital without advance directives for care ?

Performance in the inpatient setting is better. Health care professionals $(60 \%$ of attending physicians, $91 \%$ of resident physicians, $93 \%$ of nurses, and $57 \%$ of discharge planners) discuss advance directives with patients or their proxies when none exist before admission. A federal law, "The Patient Self-Determination Act," care providers in hospitals, nursing homes, and other facilities inquire about the presence of advance directives, record patient preferences in the medical record, and develop institutional policies regarding the implementation of these directives. It is possible that compliance with the law contributed to better performance in the inpatient setting.

\section{Do you discuss advance directives during the first days of hospital admission?}

Only $39 \%$ of attending physicians discuss advance directives with their patients on the first day of hospital admission. However, the gap is filled by $65 \%$ of resident physicians $(p<0.05)$ for whom this discussion is a mandatory part of the initial evaluation.

\section{Are you comfortable discussing EOL care issues with patients and/or their families?}

Most of the participants in both studies felt comfortable $(80 \%$ and $76 \%)$. Attending physicians older than 35 years were more comfortable than their younger colleagues $(80 \%$ vs $50 \%, p<0.05)$.

\section{Do you believe in palliative care at the EOL?}

Confidence in palliation grew from $86 \%$ to $97 \%(p<0.05)$. We attribute this to successes in the treatment of pain, dyspnea, cough, nausea, depression, anxiety, and other symptoms. The awareness of this progress in palliative care has increased through educational activities and from clinical experience of interdisciplinary teams.
7. Do you believe that signing a Do Not Resuscitate/Do Not Intubate (DNR/DNI) consent compromises patient care?

In both studies, a majority of respondents ( $82 \%$ and $81 \%)$ believed that a DNR/DNI consent does not compromise patient care. Indeed, by consenting to DNR, patients express only their rejection of cardiopulmonary resuscitation (CPR) but not of other life-prolonging treatments. ${ }^{9}$ However, some health care providers incorrectly perceive the DNR/DNI consent as a patient's "global decision" on a health care plan and as a rejection of aggressive treatments. Such perception leads to reluctance to order life-prolonging treatments not related to CPR. ${ }^{10}$ While obtaining the DNR/DNI consent, goals and a plan of care need to be established.

\section{Do you think that use of opioid analgesics at the} EOL hasten death?

In line with existing research, ${ }^{11}$ most of the respondents in both studies (87\% and $78 \%$ ) did not associate death with use of opioids. We did not specifically ask this question but we believe that professionals who do not associate death with use of opioids will use opioids for relief of symptoms at the EOL.

\section{Do you believe that withdrawal of active treatment is} euthanasia?

Withdrawal of active treatment is a difficult, if not the most difficult, decision in palliative medicine. Since the Cruzan v. Director, Missouri Department of Heath case in $1990,{ }^{12}$ withdrawal and withholding of treatment became legal and ethical in the USA. In a 1992 survey, 76\% of respondents (physicians, residents, and medical students) considered withholding and withdrawing life-support therapy consistent with passive euthanasia and only $24 \%$ held the view supported by the court. ${ }^{13}$ In both of our studies, the proportion of respondents accepting withdrawal of care was higher than in the cited study $(80 \%$ and $87 \%$ ). Of note, physicians younger than 35 years had a better understanding and acceptance of this concept than their colleagues older than $60(83 \%$ vs $67 \%$, $p<0.05)$.

The second part includes questions surveyed only in the second study.

10. Do terminally ill patients benefit from artificial nutrition and hydration?

About half of health care professionals (57\%) thought that terminally ill patients benefit from artificial nutrition and 
hydration. Although artificial nutrition and hydration may improve survival in certain conditions, the evidence of its benefit in patients with metastatic cancer and with end-stage dementia is conflicting. In terminally ill patients, artificial nutrition and hydration may cause suffering from edema, ascites, and aspiration. ${ }^{14}$ This palliative care area is emotionally charged for both physicians and families who often do not want to "starve to death" their loved ones.

11. Should patients who are not terminally ill be fed artificially?

Most of the respondents (82\%) agreed that these patients would benefit from artificial feeding. The existing evidence also suggests that artificial nutrition and hydration may improve survival among patients with certain conditions such as permanent vegetative state and bulbar amyotrophic lateral sclerosis. $^{14}$

12. Do you think that patients admitted to the hospital three or more times for the last 12 months with the same symptoms need palliative care evaluation?

Patients with relapsing and difficult to treat symptoms require frequent hospital admissions. It has been acknowledged that these patients need evaluation by a palliative care team with expertise in managing symptoms and defining goals of care. ${ }^{15}$ However, on this issue opinions were divided, only $50 \%$ of our participants favored such evaluation and $50 \%$ did not.

13. Is your practice influenced by your religious beliefs? A majority of health care professionals (79\%) in our study were not influenced by their religious affiliation. Certainly, decisions in health care are aligned with religious beliefs of the patients and their families/caregivers.

14. Are you aware of Medical Orders for LifeSustaining Treatment (MOLST) or Physicians Orders for Life-Sustaining Treatment (POLST)?

Widely accepted MOLST/POLST forms ${ }^{16}$ detail patients' preferences in EOL care, for instance regarding $\mathrm{CPR}$, intubation, artificial nutrition and hydration, transfusion, and use of antibiotics. These forms improve health care planning. In this area, discharge planners (social workers, case managers) were informed better (57\%) than physicians and nurses $(32 \%, p<0.001)$.

15. Does transfer to inpatient hospice improve patient care?

and

16. Does enrollment in home hospice improve patient care?
A positive attitude toward inpatient hospice care was expressed by $76 \%$ and toward home hospice care by $80 \%$ of participants. In a quality of care study, families reported fewer unmet needs of patients dying from dementia who were on hospice care. ${ }^{17}$ Benefits of early referral of cancer patients for hospice care were also shown. ${ }^{18}$

\section{Should hospice care for a patient with a terminal illness} be started as soon as the terminal diagnosis is made?

Sixty-one percent of professionals favored early enrollment in hospice care. Unfortunately, physicians do not discuss hospice options early in the disease course when patients and families can get the full benefit from hospice services. ${ }^{19}$ Development of newer cancer treatments can possibly explain the delay in hospice referrals until options of active treatment are exhausted. ${ }^{20}$

18. Do you discuss the benefits and burdens of multiple hospitalizations with your patients and their proxies?

A high hospital readmission rate incurs a substantial cost on the health care system ${ }^{1,2,21}$ and subjects chronically ill patients to multiple interventions. Various measures have been introduced such as identifying patients at risk and improving the transition of care. ${ }^{22}$ We believe that an honest discussion of the disease trajectory and goals of care is an effective intervention. As expected, in this area, attending physicians perform better than residents ( $67 \%$ vs $51 \%, p<0.05)$.

\section{Should medical futility be discussed with terminally ill patients?}

Most of the health care professionals (91\%) agreed that medical futility should be discussed with terminally ill patients and their caregivers. This attitude was shared by all groups of professionals, which is encouraging since the topic is very sensitive. In a study, ${ }^{23}$ most of the surrogates were reluctant to accept physicians' prediction of medical futility, possibly due to lack of trust in the physician's prediction, a need for the surrogate to see for themselves the futility of a situation, and the possibility that God will intercede and create a miracle.

20. Should advanced age preclude aggressive management and intensive care unit (ICU) care?

Both attending physicians (80\%) and residents $(82 \%)$ agreed that advanced age per se should not preclude aggressive management and ICU care. Although age is an important prognostic factor for patients admitted to the ICU, it should not preclude aggressive management and ICU care. This approach is supported by a study 
Table I Perception of palliative medicine by health care professionals: results of the two studies

\begin{tabular}{|l|l|l|}
\hline Area & $\begin{array}{l}\text { First } \\
\text { study }\end{array}$ & $\begin{array}{l}\text { Second } \\
\text { study }\end{array}$ \\
\hline Number of participants & 184 & 246 \\
Physicians & 100 & 158 \\
Nurses & 84 & 74 \\
Social workers/case managers & & 14 \\
\hline Answers to key questions & Yes (\%) & Yes (\%) \\
I. Participation in educational activities* & 14 & 46 \\
2. Advance directives in outpatient setting & 38 & 35 \\
5. Comfortable to discuss EOL care & 80 & 76 \\
6. Confidence in palliation at the EOL* & 86 & 97 \\
7. Correct interpretation of a DNR & 82 & 81 \\
consent & & \\
8. Opioids do not hasten death & 87 & 78 \\
9. Withdrawal of active treatment at the & 80 & 87 \\
EOL is not euthanasia & & \\
I2. Evaluation of frequently admitted & & 50 \\
patients by palliative care teams & & $76-80$ \\
I5-I6. Enrollment in hospice imporves & & \\
patient care & & \\
19. Discussion of medical futility with & & \\
teminally ill patients & & \\
\hline
\end{tabular}

Note: ${ }^{*} p<0.05$.

Abbreviations: DNR, Do Not Resuscitate; EOL, end-of-life.

revealing that patients older than 90 years did not have higher hospital mortality compared to similar patients of age 20-69 years. $^{24}$

We did not ask participants of the follow-up study whether they participated in the original study but 14 years passed and only a small number of respondents might have participated in both surveys. Therefore, participants in the two studies were two different groups of professionals.

Results of the two studies are highlighted in Table 1.

Participation in educational activities increased by the time of the follow-up study. Advanced planning of care (questions 1-4) in both outpatient and inpatient settings has not improved and requires further attention. In EOL areas (questions 5-11), perceptions of participants in both studies were aligned with palliative medicine concepts. Participants in the initial and follow-up studies felt comfortable to discuss EOL care (question 5). Confidence in palliation at the EOL (question 6) was even higher in the follow-up study. Most of the participants in both studies correctly interpreted the meaning of the DNR/DNI consent (question 7) as only exclusion of resuscitation but not of active treatment. Most of the health care professionals in both studies did not associate death with use of opioids at the EOL (question 8), a position supported by research, and did not see withdrawal of active treatment (question 9) as euthanasia, a view supported by the court. As mentioned above, recently trained physicians younger than 35 years had a better understanding of withdrawal of active treatment at the EOL. Participants in the second study revealed understanding of the disease trajectory in chronic progressive illness and were ready to discuss the burden of multiple admissions (question 18), medical futility (question 19), and enrollment in hospice care (questions 15-17).

Age and experience were associated with better planning of care in the outpatient setting (question 2), higher confidence in discussing EOL issues (question 5), and burdens of multiple admissions (question 18). However, younger physicians had a better understanding of withdrawal of active treatment (question 9). Religion did not influence perception of palliative care (question 13).

On the interaction between palliative and interdisciplinary teams (question 12), opinions of participants were evenly divided. This came as a surprise but allowed us to test our hypothesis that such interaction is essential in perception of palliative medicine concepts. Indeed, further statistical analysis revealed that the position on this issue correlated with attitude towards multiple other areas such as advanced care planning, awareness of MOLST/POLST forms, interpretation of the DNR consent, use of opioids at the EOL, use of ICU care, multiple admissions, and hospice care. Participants who favored co-management with palliative teams had the approach to these core issues aligned with concepts currently accepted in palliative medicine. We call such perception and acceptance of palliative medicine concepts a "palliative attitude."

\section{Discussion}

Perception of palliative medicine concepts by participants in our studies was aligned with current concepts supported by research, clinical practice, and legal rulings. Attendance of educational activities increased and confidence in palliative care was higher in the follow-up study. In other areas, the results of the two studies were close. Although we would like to see better results in the follow-up study, the participants in the second study were a different group of health care professionals. In the follow-up study, interaction with palliative care teams and learning through clinical practice was the key factor in understanding and 
accepting concepts of palliative medicine and development of a "palliative attitude" by health care professionals. We could not associate perception of palliative medicine with educational activities in the form of lectures, seminars, and workshops, but we remain committed to these forms of education.

\section{Conclusions}

Perception of palliative medicine concepts by health care professionals was learned at a teaching community hospital in two studies separated by 14 years. The results of the two studies were essentially similar; attendance of educational activities and confidence in palliative care were higher 14 years later. In most of the areas, perception of palliative medicine was aligned with current concepts. We call this acceptance of palliative medicine a "palliative attitude." Active interaction with palliative care teams is key to the development of such "palliative attitude." A "palliative attitude" of health care professionals is essential for the promotion of palliative medicine.

\section{Limitations}

Our study has limitations. First, we did not ask participants of the follow-up study whether they participated in the original study. Prior experience could have made their participation easier and create a "positive bias" in their responses. Second, the spectrum of participants in the second study was broader than in the first study which might have affected the comparison of the results. Third, the questionnaires of the two studies were not exactly similar; the second study addressed a wider range of issues.

\section{Acknowledgments}

The authors are grateful to Dr William M. Briggs for statistical processing of the data.

\section{Disclosure}

The authors report no conflicts of interest in this work.

\section{References}

1. Aldridge M, Kelley A. The myth regarding the high cost of end - of life care. Am J Public Health. 2015;105(12):2411-2415. doi:10.2105/ AJPH.2015.302889

2. Moses H, Matheson DH, Dorsey ER, et al. The anatomy of healthcare in the United States. JAMA. 2013;310(18):1947-1963. doi:10.1001/ jama.2013.281425

3. The Palliative Care Act - Department of Health. Available from: www. health.ny.gov. Accessed April 2, 2011.
4. $\mathrm{R}$ version 3.4.2. R Core Team (2017). R: A language and environment for statistical computing. $\mathrm{R}$ foundation for statistical computing. Vienna, Austria. Available from: www.R-project.org/. Accessed February 6, 2018.

5. Ramsaroop SD, Reid MC, Adelman RD. Completing an advance directive in the primary care setting: what do we need for success? J Am Geriatr Soc. 2007;55(2):277-283. doi:10.1111/j.1532-5415.2007.01065.x

6. Emanuel LL, Danis M, Pearman RA, Singer PA. Advance care planning as a process: structuring the discussions in practice. $J \mathrm{Am}$ Geriatr Soc. 1995;43(4):440-446.

7. Smucker WD, Ditto PH, Moore KA, et al. Elderly outpatients respond favorably to a physician-initiated advance directive discussion. J Am Board Fam Pract. 1993;6(5):473-482.

8. Greco PJ, Schulman KA, Lavizzo-Mourey R, Hansen-Flaschen J. The patient self-determination act and the future of advance directives. Ann Intern Med. 1991;115(8):639-643.

9. Beach MC, Morrison RS. The effect of do-not-resuscitate orders on physician decision-making. $J$ Am Geriatr Soc. 2002;50 (12):2057-2061.

10. Smith CB, Bunch O'Neill L. Do not resuscitate does not mean do not treat: how palliative care and other modalities can help facilitate communication about goals of care in advance illness. Mt Sinai $J$ Med. 2008;75(5):460-465. doi:10.1002/msj.20076

11. Sykes N, Thorns A. The use of opioids and sedatives at the end of life. Lancet Oncol. 2003;4(5):312-318.

12. Gaudin AM. Cruzan v. Director, Missouri department of health: to die or not to die: that is the question - but who decides? LA Law Rev. 1991;51(6):1308-1345.

13. Caralis PV, Hammond JS. Attitudes of medical students, housestaff, and faculty physicians toward euthanasia and termination of life-sustaining treatment. Crit Care Med. 1992;20(5):683-690.

14. Casarett D, Kapo J, Caplan A. Appropriate use of artificial nutrition and hydration - fundamental principles and recommendations. $N$ Engl J Med. 2005;353(24):2607-2612.

15. Weissman DE, Meier DE. Identifying patients in need of a palliative care assessment in the hospital setting: a consensus report from the center to advance palliative care. $J$ Palliat Med. 2011;14(1):17-23. doi: $10.1089 /$ jpm.2010.0347

16. Medical Orders for Life-sustaining Treatment (MOLST). Available from: www.health.ny.gov/forms/doh-5003pdf. Accessed September $2,2012$.

17. Teno JM, Gozalo PL, Lee IC, et al. Does hospice improve quality of care for persons dying from dementia? J Am Geriatr Soc. 2011;59 (8):1531-1536. doi:10.1111/j.1532-5415.2011.03505.x

18. von Gunten CF, Lutz S, Ferris FD. Why oncologists should refer patients earlier for hospice crae. Palliat Support Care. 2011;25(13):1-8.

19. McGorty EK, Bornstein BH. Barriers to physicians' decisions to discuss hospice: insights gained from the United States hospice model. J Eval Clin Pract. 2003;9(3):363-372.

20. Mintzer DM, Zagrabbe K. On how increasing numbers of newer cancer therapies further delay referral to hospice: the increasing palliative care imperative. Am J Hosp Paliat Care. 2007;24 (2):126-130. doi:10.1177/1049909106297363

21. Jencks SF, Williams MV, Coleman EA. Rehospitalizations among patients in the Medicare fee-for-service program. $N$ Engl $J$ Med. 2009;360:1418-1428. doi:10.1056/NEJMsa0803563

22. Kripalani S, Theobaldd CN, Anctill B, Vasilevskis EE. Reducing hospital readmission rates: current strategies and future directions. Annu Rev Med. 2014;65:471-485. doi:10.1146/annurev-med-022613090415

23. Zier LS, Burack JH, Micco G, et al. Surrogate decision makers' responses to physicians' predictions of medical futility. Chest. 2009;136(1):110-117. doi:10.1378/chest.08-2753

24. Demoule A, Cracco C, Lefort Y, et al. Patients aged 90 years or older in the intensive care unit. J Gerontol A Biol Sci Med Sci. 2005;60 (1):129-132. 


\section{Publish your work in this journal}

The Journal of Multidisciplinary Healthcare is an international, peerreviewed open-access journal that aims to represent and publish research in healthcare areas delivered by practitioners of different disciplines. This includes studies and reviews conducted by multidisciplinary teams as well as research which evaluates the results or conduct of such teams or healthcare processes in general. The journal covers a very wide range of areas and welcomes submissions from practitioners at all levels, from all over the world. The manuscript management system is completely online and includes a very quick and fair peer-review system. Visit http://www.dovepress.com/testimonials. php to read real quotes from published authors. 